NBER WORKING PAPER SERIES

\title{
ON THE DISTRIBUTIONAL CONSEQUENCES OF CHILD LABOR LEGISLATION
}

\author{
Dirk Krueger \\ Jessica Tjornhom Donohue \\ Working Paper 10347 \\ http://www.nber.org/papers/w10347 \\ NATIONAL BUREAU OF ECONOMIC RESEARCH \\ 1050 Massachusetts Avenue \\ Cambridge, MA 02138 \\ March 2004
}

We would like to thank Daron Acemoglu, Moshe Hazan, Tim Kehoe, Krishna Kumar, Ellen McGrattan, Lee Ohanian, Fabrizio Perri, Edward Prescott, Warren Weber, Christian Zimmermann, two anonymous referees, an associate editor, and seminar participants at the Minneapolis FED and Stanford for many helpful comments. We bear full responsibility for all remaining errors. Krueger acknowledges financial support from the NSF under grant SES 0004376. The views expressed herein are those of the authors and not necessarily those of the National Bureau of Economic Research.

C 2004 by Dirk Krueger and Jessica Tjornhom Donohue. All rights reserved. Short sections of text, not to exceed two paragraphs, may be quoted without explicit permission provided that full credit, including (C) notice, is given to the source. 
Technological Innovations and Endogenous Changes in U.S. Legal Institutions, 1790-1920

Dirk Krueger and Jessica Tjornhom Donohue

NBER Working Paper No. 10347

March 2004

JEL No. I28, J22, D31, O10

\section{$\underline{\text { ABSTRACT }}$}

In this paper we construct a dynamic heterogeneous agent general equilibrium model to quantify the effects of child labor legislation on human capital accumulation and the distribution of wealth and welfare. Crucial model elements include a human capital externality in the market sector, an informal home production sector in which child labor laws cannot be enforced, uninsurable idiosyncratic income risk, borrowing constraints, and endogenous wage and interest rate determination in general equilibrium. We calibrate the model to US data around 1880 and find that the welfare consequences for individual households of a transition to policies that restrict child labor or provide tax-financed free education depend crucially on the main source of a households' income. Whereas households with significant financial asset holdings unambiguously lose from any government intervention, high-wage workers benefit most from a ban on child labor, while lowwage workers benefit most from free education. Based on a utilitarian social welfare function, the introduction of free education results in substantial welfare gains, in the order of $3 \%$ of consumption, mainly because it leads to higher human capital accumulation. A child labor ban, in contrast, induces (small) welfare losses because it reduces income opportunities for poor families without being effective in stimulating education attainment.

Dirk Krueger

Department of Economics

University of Pennsylvania

3718 Locust Walk

Philadelphia, PA 19104

and NBER

dkrueger@econ.upenn.edu

Jessica Tjornhom Donohue

State Street Associates

$138 \mathrm{Mt}$. Auburn Street

Cambridge, MA 02138 


\section{Introduction}

A child that works is less likely to receive a good education. If education, and thus the accumulation of human capital, is associated with positive externalities, implying a divergence of private and social returns to human capital, then a benevolent government should possibly intervene in parents' private schooling decisions, even if parents are altruistic. ${ }^{1}$ Even without externalities, credit market imperfections that prevent parents from borrowing against the future labor income of their children may induce inefficiently low investment into education.

On the other hand child labor contributes significantly to household income, ${ }^{2}$ particularly in developing economies. Thus policy makers deciding whether or not to adopt child labor legislation ${ }^{3}$ face the crucial trade-off between distorting private decisions and correcting potential inefficiencies arising from human capital externalities and credit market frictions. In addition, the costs and benefits of such legislation are not evenly distributed among the population. The poor laborer who cannot afford to send his children to school may feel very differently about these policy innovations than the wealthy member of the upper class whose own children receive an education whether or not child labor legislation is in place and for whom children are an important source of cheap labor for their factories.

In this paper we build a dynamic heterogeneous agent general equilibrium model to assess the quantitative importance and distributional consequences of these trade-offs. We study two possible policy reforms: (1) a ban on child labor and (2) tax-financed free schooling. ${ }^{4}$ Our main focus is on the welfare consequences of these policies across different groups of the population. By documenting the winners and losers of child labor legislation reforms our paper provides predictions about which households (that is, their economic characteristics) one should expect to support and to oppose such reforms.

To qualitatively evaluate our model predictions and to guide us in the calibration of our model economy, we look to the United States of the second half of the 19th century - a time period of heated debates around child labor legislation. Our reading of this historical record for the U.S. indicates that economic status (one's position in the income and wealth distribution) was a crucial element in determining support or opposition of child labor bans and publicly funded education in the U.S. While the policy reforms and the economic forces at work in the 19th century U.S. are very similar to those of many developing countries in the present, one key difference makes us prefer the historical U.S. evidence

\footnotetext{
${ }^{1}$ Government intervention may obviously be justified if parents do not value the well-being of their children, whereas the social welfare function of the benevolent government does.

${ }^{2}$ See, among others, Psacharopoulos (1997) and Levison, et. al. (2001) for empirical work on the contribution of child labor to household income in developing countries and Ensign (1969) and Trattner (1970) for a historical perspective of this subject.

${ }^{3}$ When we use the term "child labor legislation", from now on we refer to both child labor bans as well as schooling laws.

${ }^{4}$ We will demonstrate below that a tax-financed mandatory schooling law and a combination of child labor bans and schooling laws have consequences very similar to those of tax-financed free schooling.
} 
as point of comparison. The lack of international political pressure that might lead a developing nation to adopt such legislation, even if it is not in the interest of its citizens, allows us to better compare our model results with the U.S. historical record. We do believe, however, that the results derived from our model provide insights into the political debate of child labor legislation in developing countries today as well, and thus we use some features of developing economies as motivation for our theoretical model.

We find that the welfare consequences for individual households of a transition to policies that restrict child labor or provide tax-financed free education depend crucially on the main source of a households' income. Households with significant financial asset holdings unambiguously lose from any government intervention because it reduces labor supply from children and thus leads to a decline (at least initially) in the capital-labor ratio and thus the return to capital. Workers with high labor productivity and no assets are the only group of the population benefitting from a ban on child labor (even though this policy has no impact on educational attainment and thus the size of the human capital externality), since the reduction of labor supply increases their wages and they do not rely on income from their own children working in the market sector.

Meanwhile, providing free, linear income tax-financed education benefits income-poor families to the largest extent, because it provides them with otherwise unaffordable schooling opportunities, financed mainly by taxes on high (capital and labor) income households. Since this policy is increases average human capital in the economy substantially, all groups but the wealthiest $7 \%$ of the population benefit from such a policy innovation. The welfare consequences from the free education law are substantial: while the steady state welfare gains, based on a utilitarian welfare functional, amount to more than $3 \%$ of consumption, the gains taking the transitional costs into account explicitly still range between $0.5 \%-1 \%$ of consumption for most households. A child labor ban, in contrast, induces small steady state and somewhat bigger transitional welfare losses, because it reduces income opportunities for poor families, without being effective in stimulating education attainment.

The next section outlines the model's crucial elements and provides a discussion of the related literature and the historical context. In Section 3 we present the model and section 4 describes our policy experiments. Section 5 explains the calibration of the model for our numerical exercises. In Section 6 we present our main results, including a sensitivity analysis of key parameters, before we compare the empirical predictions of the model with the historical record for the U.S. in section 7. This section also includes a concluding discussion of the implications of our findings for the discussion about child labor legislation in currently developing countries. 


\section{Key Model Elements and Related Literature}

\subsection{Model Elements}

Our model contains six key elements designed to evaluate the economic tradeoffs associated with child labor and schooling legislation: (1) parental altruism and paternalism; (2) uninsurable idiosyncratic income risk (3) the presence of potentially binding borrowing constraints (4) human capital externalities in the market production sector (5) a formal market- and informal household production sector and (6) price determination in dynamic general equilibrium . We now justify each feature of the model and discuss its relation to the existing literature.

In the tradition of Ben-Porath (1967) and Becker and Barro (1988), we assume that parents are altruistic and care about their children's future utility. Thus,instead of using them as a tools for generating household income (as in, e.g., Gupta, 2000), parents in our model may send their children to school out of concern for their future earnings potential and thus overall lifetime utility. The altruism assumption has been used extensively in the literature on child labor, human capital accumulation and growth. Examples include Dessy (2000), Doepke (2003), Fernández-Villaverde (2001) and Hazan and Berdugo (2002). Parents are also paternalistic in our model in that they make all economic decisions for their children, including their time allocation.

Since parents internalize the well-being of their children, the rationale for government intervention in our model stems from market imperfections. ${ }^{5}$ As a second key model element, households face idiosyncratic labor income risk against which no insurance contracts can be purchased. Child labor is used, as a partial substitute for missing insurance markets, to stabilize family income. Empirical studies show that lower-income parents often send their children to work instead of (or in addition to) school in order to supplement family income and smooth income shocks. According to Grootaert and Kanbur (1995), "Child labor can be part of a strategy to minimize the risk of interruption of a household's income stream, and hence to reduce the potential impact of job loss by a family member, of a failed harvest, etc." (p.194). Jacoby and Skoufias (1997) find that child labor helps to smooth income of rural Indian families,consistent with poorly developed markets for credit and risk. Uninsurable labor income risk gives rise to a nondegenerate wealth distribution within the population in our model, allowing for a meaningful analysis of child labor legislation's distributional welfare consequences, the key question addressed in this paper. This feature endogenously generates both poor households whose only income stems from labor earnings and wealthy households who derive a substantial fraction of their income from asset returns.

Third, we assume that adults cannot borrow against their children's income to finance their education or to increase current household consumption. Access to credit markets is limited for most individual households in developing nations,

\footnotetext{
${ }^{5}$ Glomm (1997), Dessy (2000), and Pallage and Zimmermann (2000) also use the assumption of parental paternalism.
} 
including the U.S. in the 19th century. Income from child labor thus plays an important role for poor households for which credit does not exist. In making this assumption, which limits a households' ability to self-insure ${ }^{6}$, we follow a large body of the literature studying optimal consumption and saving choices under uncertainty in general equilibrium (see e.g. Aiyagari (1994), Krusell and Smith (1998) and many others).

A fourth key model feature that gives rise to potential market failures is a human capital externality in production, as proposed by Lucas(1988), which enhances both the marginal products of labor and capital in the market production sector. Consequently the social returns from education exceed the corresponding private returns. By incorporating "the traditional argument for government intervention in child labor markets" (Basu (1999) p. 1084), we attempt to assess the quantitative importance of human capital externalities for the justification of child labor legislation.

As a fifth model ingredient we introduce both a formal market and an informal household production sector. Their distinguishing characteristics is that child labor bans are enforceable in the market sector, but not in the household sector. Including an informal household production sector is necessary given our objective, because, in order to properly model the allocation of children's time between school and work, we must allow them to be employed in activities besides working for wages. Many empirical studies find that a good portion of child labor occurs in the household sector in developing countries and the same was true in the U.S. historical context. ${ }^{7}$ The distinction of household and market sectors, also used in Basu and Van (1998), Levison et. al. (2001), and Dessy (2000) allows us to evaluate the widespread conjecture that the sole effect of child labor bans is to drive children into less efficient production activities instead of increasing educational attainment, particularly among the poor.

Lastly, we place our households into an overlapping generations dynamic general equilibrium frame work in which factor prices are endogenously determined over time. Because our model contains dynamic human capital and asset accumulation decisions along transition paths induced by a reform in child labor legislation, changing factor prices have important distributional consequences. An increase in wages benefits the poor laborer and a fall in the interest rate hurts the rich capitalist. As we intuitively argued above and quantitatively demonstrate below, these effects are crucial for determining the welfare consequences that policy reforms engender among various groups of the population.

One final comment on human capital and economic growth is in order. In our model human capital is a potential engine of growth. Induced by a policy reform, human capital accumulation may increase, leading to economic growth along the transition to a new steady state. However, these growth effects are, by construction, transitory since our model does not exhibit endogenous growth (as in, e.g. Lucas, 1988). We decided against using an endogenous growth model

\footnotetext{
${ }^{6}$ Note that we $d o$ allow dynasties to self-insure against intergenerational labor income fluctuations by accumulating assets.

${ }^{7}$ Grootaert and Kanbur (1995), for example, report very high participation rates in family businesses, farms and housework (up to $68 \%$ of children under 15 ).
} 
in which human capital accumulation is the engine of permanent growth for the following reason. The debate of whether economic policies have persistent effects on growth rates (rather than just level effects) is very much unsettled. Making the conservative assumption of no long-run growth effects of child labor policies prevents us from overstating the benefits of such laws, since permanent growth effects from these laws would likely exceed the benefits from transitory human capital accumulation-induced growth in our model. ${ }^{8}$

\section{$2.2 \quad$ Related Literature}

Our paper continues a growing literature that uses theoretical models to evaluate the consequences of child labor legislation. ${ }^{9}$ This literature is motivated by the descriptive and empirical evidence about the origins and effects of child labor legislation in now industrialized countries in the 19th century as well as in currently developing countries. While a detailed summary of the historical and development literature goes well beyond the scope of this paper we briefly summarize the main stylized facts surrounding the adoption of child labor legislation in the 19th century U.S.. Since our model has explicit implications for the distribution of welfare consequences from child labor legislation, in section 7 we will discuss to what extent the historical record and the results of our model coincide. ${ }^{10}$

In Colonial North America work by children was not only common but expected by society (see Hindman (2002), p. 45-47). The first child labor laws were passed in New England in the 1840; however, few states outside this region followed until after 1880 (see Nardinelli (1990), p. 129). The public provision of education tended to predate child labor bans in most states (see Landes and Solmon, 1972). Since our model analysis will determine the economic status of households predicted to gain and lose most from child labor legislation, it is crucial to identify which groups of the population favored and which groups opposed child labor legislation historically. Nardinelli (1990) identifies workers, primarily those organized in unions, as the main group supporting child labor laws based on economic incentives. It is important to note that their first efforts to curb child labor focused on equalizing education opportunities, rather than child labor bans directly (see Hindman (2002), p. 49). Interestingly, unorganized workers, in particular those from poor households who would see family income decline as a result of child labor bans, often opposed such legislation (see

\footnotetext{
${ }^{8} \mathrm{~A}$ second, equally important reason is computational. Given our focus on the distributional impacts from child labor legislation our model has a rich cross-sectional distribution of types, induced by uninsurable idiosyncratic uncertainty. Endogenous growth would make the economy nonstationary, and would require us to compute a balanced growth path along which all variables grow at an endogenously determined growth rate, yet the cross-sectional distribution of assets remains (after appropriate normalization) constant. To the best of our knowledge such a model (the incorporation of an Aiyagari (1994) economy into an endogenous growth model) has not yet been solved numerically.

${ }^{9}$ See Basu (1999) for an excellent survey of the theoretical and empirical literature.

${ }^{10}$ For a summary of the development literature see Basu (1999) and the many references therein.
} 
Nardinelli (1990), p. 143). ${ }^{11}$ The most powerful and vocal opposition against child legislation came, not surprisingly, from the capitalists employing child labor and their trade associations (see Hindman (2002), p. 53-57). Were child labor bans effective in curbing child labor? Nardinelli (1990) and Moehling (1999) suggest that the decline of child labor in the late 19th and early 20th century in the U.S. cannot be attributed to this legislation,but rather to other economic factors that made industrial child labor obsolete. We will compare these historical facts to the predictions of our theoretical model below.

Other model-based studies of child labor legislation include Basu and Van (1998), who combine Stone-Geary preferences with the assumption that adult and child labor are substitutes to generate the existence of multiple equilibria in the labor market. A ban on child labor can then be used to implement the desired equilibrium. Baland and Robinson (2000) construct a model where inefficient child labor occurs in equilibrium if altruistic parents, because of credit market imperfections as in our model, fail to fully internalize the negative impact of child labor on human capital accumulation. Neither model, however, introduces heterogeneity, and thus cannot fully address the impact of child labor legislation on the distribution of wealth and welfare.

Dessy and Knowles (2001) link income inequality to the emergence of child labor laws. In their model parents have time-inconsistent preferences with respect to their children's utility. Consequently, parents benefit from a commitment device such as a child labor ban. Our model, in contrast, postulates timeconsistent preferences; child labor legislation is justified on normative grounds by human capital externalities and capital market imperfections. Also, while their main focus is the analysis of the conditions under which a mandatory education law emerges politically, we devote more attention to the distribution of the welfare consequences of such policy innovation, without explicitly modelling the political process that leads to it.

Doepke (2003), while primarily concerned with the interaction of economic growth and fertility, also studies the distributional effects of child labor legislation. In his model, heterogeneity is confined to a distinction between skilled and unskilled households, whereas in ours a nondegenerate wealth distribution is crucial for the study of the distributional effects of child labor legislation. Dessy (2000) presents a model of growth with endogenous fertility where, as in Doepke (2003), human capital is the only source of heterogeneity and studies compulsory education measures to alleviate child labor. Finally, Pallage and Zimmermann (2000) present a two-country growth model to investigate the use of transfers from a rich to a poor country in order to secure compliance with a child labor ban. To these studies our paper adds richness with respect crosssectional income and wealth heterogeneity, in order to study the distributional consequences of child labor and education legislation.

\footnotetext{
${ }^{11}$ For Britain, Cunningham (1996) writes that "child labor founds its strongest and most persistent advocates within the working class, much to the embarrassment of trade union leaders." This citation is taken from Doepke and Zilibotti (2003).
} 


\section{The Model}

The economy is populated by two-period lived overlapping generations. Each household consists of one adult and one child, and there is continuum of measure one of both adults and children at each date $t$. The single good in this economy is produced in both the market sector and the household sector and can be used for either consumption or investment.

\subsection{Technology}

In the market sector the representative firm operates the technology

$$
F\left(K_{t}, N_{t}, \bar{H}_{t}\right)=A K_{t}^{\theta} N_{t}^{1-\theta} \bar{H}_{t}^{\gamma}
$$

with $A>0$ and $\theta \in(0,1)$. Here $K_{t}$ is the aggregate level of physical capital at time $t$ and $N_{t}$ represents the aggregate labor input at time $t$, measured in efficiency units. The average human capital in the economy is denoted by $\bar{H}_{t}$; its value is taken as given by firms and households when making their economic decisions. ${ }^{12}$ The parameter $\gamma \geq 0$ measures the extent of the human capital externality in production; its size will turn out to be an important determinant of the welfare consequences of child labor legislation.

In the household sector labor supplied by a child, $n_{t}$, is used to produce the non-storable consumption good. The household technology is specific to and owned by each household, and all production accrues to that household. Production using this technology features decreasing returns to scale with respect to labor input and is given by

$$
f\left(n_{t}\right)=\left(y^{c} n_{t}\right)^{\alpha}
$$

where $\alpha \in(0,1)$ and $y^{c}>0$ are parameters, and $y^{c}$ measures labor productivity of a child relative to that of an adult.

The level of human capital of an adult, which determines her labor income as described below, is determined by a human capital production function of the form

$$
h_{t+1}=1+\varphi s_{t} l
$$

where $\varphi, l>0$ are parameters ${ }^{13}$ and $s_{t} \in\{0,1\}$ denotes the parent's discrete choice of whether or not to send their child to school, with $s_{t}=1$ if the parent sends the child to school and 0 otherwise. The parameter $l$ indicates the time necessary to go to school. Thus we normalize the human capital of an adult with no education to 1 . Given this specification there are two possible values of human capital for adults in any period $t+1$ : $h_{t+1} \in\{1,1+\varphi l\}$. Note for calibration purposes that $\varphi l$ will equal the wage premium for educated workers.

\footnotetext{
${ }^{12}$ Hence firms face constant returns to scale with respect to the production factors they choose. Thus the number of firms is indeterminate in equilibrium, and our assumption of a single representative firm is without loss of generality.

${ }^{13}$ The parameter $\varphi$ captures, in a reduced form, the effects on human capital formation of the amount of spending on each child, peer group effects as well as the quality of teachers.
} 


\subsection{Endowments and Preferences}

Adults face idiosyncratic shocks to labor productivity. The stochastic process for adult labor productivity follows a finite state Markov process with support $Y=\left\{y^{1}, \ldots y^{N}\right\}$ and transition function $\pi$, where

$$
\pi\left(y^{\prime} \mid y\right)=\operatorname{prob}\left(y_{t+1}=y^{\prime} \mid y_{t}=y\right)
$$

We assume that $\pi$ has a unique invariant distribution $\Pi$, equal to the crosssectional distribution of labor productivities at period 1 (and hence at any future date). Furthermore, we assume that the average labor productivity of an adult equals $\sum_{y} y \Pi(y)=1$. By assumption labor productivity shocks are uninsurable in that households cannot write explicit contracts that are contingent on the current realization of $y_{t}$. They can, however, self-insure by accumulating risk-free capital. In the benchmark version of our model relative child labor productivity $y_{c}$ is non-stochastic; we will explore the implications of idiosyncratic uncertainty with respect to child labor productivity in our sensitivity analysis, in section 6.3.

Adults in period $t$ are characterized by the vector $\left(y_{t}, h_{t}, k_{t}\right)$, where $y_{t}$ is idiosyncratic labor productivity, $h_{t}$ is the individual level of human capital, and $k_{t}$ the level of individual capital, the only financial asset available in this economy. We use $\Phi_{t}\left(y_{t}, h_{t}, k_{t}\right)$ to denote the measure of adult agents of type $\left(y_{t}, h_{t}, k_{t}\right)$ at date $t$, and $\Phi_{1}\left(y_{1}, h_{1}, k_{1}\right)$ to denote the initial distribution of adults. Each adult in the economy is endowed with one unit of time, which she supplies inelastically to the market sector. The effective labor supply of an adult of type $\left(y_{t}, h_{t}, k_{t}\right)$ then equals $y_{t} h_{t}$.

Adults of generation $t$ have preferences over their own consumption in period $t$ and the expected future utility of their child. We assume that preferences can be represented by

$$
u\left(c_{t}\right)+\beta E_{t}\left[V_{t+1}\left(y_{t+1}, h_{t+1}, k_{t+1} ; \Phi_{t+1}\right) \mid y_{t}\right]
$$

where $c_{t}$ is adult consumption in period $t$, and $y_{t+1}, h_{t+1}$ and $k_{t+1}$, respectively, are the idiosyncratic labor productivity, individual level of human capital, and physical capital of generation $t+1$. The function $V_{t+1}$ denotes the maximal utility a child can obtain if he or she reaches adulthood with labor productivity shock $y_{t+1}$, human capital $h_{t+1}$ and assets $k_{t+1}$. Furthermore $\Phi_{t+1}$ denotes the distribution over types of adults in $t+1$ and $E_{t}\left[. \mid y_{t}\right]$ denotes the expectation operator, conditional on the realization of the idiosyncratic shock $y_{t}$. Finally, the parameter $\beta$ is the parental discount factor for the utility of their children and thus a measure of altruism.

In the model each parent has one child. Children do not consume ${ }^{14}$ but are endowed with one unit of time. Parents allocate a child's time to school and work in the market and household sectors. Sending a child to school involves two costs: a direct cost of paying tuition (unless a schooling law is in place that

\footnotetext{
${ }^{14}$ Obviously one can interpret $c_{t}$ as total household consumption, given that the number of household members alive at any given time is fixed at 2 .
} 
finances public schools via income taxation) and the opportunity cost of time spent in school rather than at work in the market or household sector. Parents face the following constraint for the allocation of time of their child:

$$
s_{t} l+m_{t}+n_{t}=1
$$

where $m_{t}$ denotes a child's time spent working in the market sector.

\subsection{Government Policies}

We consider combinations of three types of child labor legislation. Let $\nu_{t}$ be an indicator variable that equals 0 if there is no ban on child labor and 1 is there is a ban on child labor. Let $\mu_{t}$ be an indicator variable that equals 1 if education is free. Finally let $\tau_{t}$ denote the flat income tax rate used to raise the revenue for public education. We assume that $\tau_{t}$ is set so as to obtain government budget balance in each period. Agents in the model take the sequence of government policies, $\left\{\nu_{t}, \mu_{t}, \tau_{t}\right\}_{t=1}^{\infty}$ as exogenously given.

\subsection{The Household Problem}

Adults with characteristics $\left(y_{t}, h_{t}, k_{t}\right)$ in period $t$ choose their own consumption, $c_{t}$, the time their child spends in the market and household sectors, $m_{t}$ and $n_{t}$, whether they send their child to school, $s_{t}$, the level of their child's human capital, $h_{t+1}$, and the size of their bequest, $k_{t+1}$, to solve

$V_{t}\left(y_{t}, h_{t}, k_{t} ; \Phi_{t}\right)=\max _{c_{t}, m_{t}, n_{t}, s_{t}, h_{t+1}, k_{t+1}}\left\{u\left(c_{t}\right)+\beta \sum_{y_{t+1} \in Y} \pi\left(y_{t+1} \mid y_{t}\right) V_{t+1}\left(y_{t+1}, h_{t+1}, k_{t+1} ; \Phi_{t+1}\right)\right\}$

subject to the constraints (3), (6), the constraints

$$
\begin{aligned}
0 & \leq m_{t}, n_{t} \leq 1 \\
c_{t} & \geq 0, k_{t+1} \geq 0 \\
s_{t} & \in\{0,1\}
\end{aligned}
$$

and the budget constraints

$c_{t}+\kappa\left(1-\mu_{t}\right) s_{t}+k_{t+1} \leq\left(1-\tau_{t}\right)\left[\left(y_{t} h_{t}+\left(1-\nu_{t}\right) y^{c} m_{t}\right) w_{t}+r_{t} k_{t}\right]+k_{t}+f\left(y^{c} n_{t}\right)$

where $w_{t}$ is the real wage per efficiency unit of labor in the market sector and $r_{t}$ is the real interest rate. Note that the restriction $k_{t+1} \geq 0$ imposes the assumption of non-negative bequests, ruling out parental borrowing against a child's labor income. The parameter $\kappa$ denotes the real resource cost of education per pupil that parents must pay for their child's education. Households are assumed to behave competitively in that they take government policies $\left(\nu_{t}, \mu_{t}, \tau_{t}\right)$, prices 
$\left(w_{t}, r_{t}\right)$ and the distribution of types $\Phi_{t}$ as exogenously given and beyond their control. ${ }^{15}$

\subsection{Competitive Equilibrium}

We are now ready to define a competitive equilibrium for our economy. Let $Z=Y \times \mathbf{R}_{+} \times \mathbf{R}_{+}$be the set of all possible $\left(y_{t}, h_{t}, k_{t}\right)$. Let $\mathcal{B}\left(\mathbf{R}_{+}\right)$be the Borel $\sigma$-algebra of $\mathbf{R}_{+}$and $\mathcal{P}(Y)$ be the power set of $Y$. Finally let $\mathcal{B}(Z)=$ $\mathcal{P}(Y) \times \mathcal{B}\left(\mathbf{R}_{+}\right) \times \mathcal{B}\left(\mathbf{R}_{+}\right)$and $\mathbf{M}$ be the set of all finite measures on the measurable space $(Z, \mathcal{B}(Z))$.

Definition 1 Given the initial distribution $\Phi_{1}$, and child labor legislation $\left\{\nu_{t}, \mu_{t}\right\}_{t=1}^{\infty}$ a competitive equilibrium is a sequence of individual functions for the household $\left\{V_{t}, c_{t}, m_{t}, n_{t}, s_{t}, h_{t+1}, k_{t+1}: Z \times \mathbf{M} \rightarrow \mathbf{R}\right\}_{t=1}^{\infty}$, sequences of production plans for the firm $\left\{N_{t}, K_{t}\right\}_{t=1}^{\infty}$, factor prices $\left\{w_{t}, r_{t}\right\}_{t=1}^{\infty}$, aggregate human capital levels $\left\{\bar{H}_{t}\right\}_{t=1}^{\infty}$, government taxes $\left\{\tau_{t}\right\}_{t=1}^{\infty}$, and a sequence of measures $\{\Phi\}_{t=1}^{\infty}$ such that, for all $t$,

1. (Maximization of Households): Given $\left\{w_{t}, r_{t}, \bar{H}_{t}\right\}$ and $\left\{\nu_{t}, \mu_{t}, \tau_{t}\right\}$ the functions $\left\{V_{t}\right\}$ satisfy (7) and $\left\{c_{t}, m_{t}, n_{t}, s_{t}, h_{t+1}, k_{t+1}\right\}$ are the associated policy functions

2. (Marginal Product Pricing): The prices $w_{t}$ and $r_{t}$ satisfy

$$
\begin{aligned}
& w_{t}=A(1-\theta)\left(\frac{K_{t}}{N_{t}}\right)^{\theta} \bar{H}_{t}^{\gamma} \\
& r_{t}=A \theta\left(\frac{N_{t}}{K_{t}}\right)^{1-\theta} \bar{H}_{t}^{\gamma}-\delta .
\end{aligned}
$$

3. (Government Budget Constraint): If education is publicly funded, then

$$
\tau_{t}=\frac{S_{t} \kappa}{w_{t} N_{t}+r_{t} K_{t}}
$$

and else $\tau_{t}=0$ for all $t \geq 1$.

4. (Market Clearing):

$$
\begin{aligned}
& \int c_{t}\left(y_{t}, h_{t}, k_{t}\right) d \Phi_{t}+\kappa \int s_{t}\left(y_{t}, h_{t}, k_{t}\right) d \Phi_{t}+K_{t+1} \\
= & A K_{t}^{\theta} N_{t}^{1-\theta} \bar{H}_{t}^{\gamma}+\int\left[y^{c} n_{t}\left(y_{t}, h_{t}, k_{t}\right)\right]^{\alpha} d \Phi_{t}+(1-\delta) K_{t}
\end{aligned}
$$

\footnotetext{
${ }^{15}$ The aggregate distribution $\Phi_{t}$ needs to be included as a state variable in the household's problem because it determines the aggregate stocks of physical and human capital as well as aggregate labor supply. These in turn imply the factor prices, $r_{t}$ and $w_{t}$, which households need to know in order to solve their maximization problem. For the same reason, households need to forecast tomorrow's distribution over types, $\Phi_{t+1}$, as it affects the maximization problem that their children will solve (and hence the child's maximal utility, given their individual state $\left.\left(y_{t+1}, h_{t+1}, k_{t+1}\right)\right)$.
} 


$$
\begin{aligned}
N_{t} & =\int\left(y_{t} h_{t}+y^{c} m_{t}\left(y_{t}, h_{t}, k_{t}\right)\right) d \Phi_{t} \\
K_{t+1} & =\int k_{t+1}\left(y_{t}, h_{t}, k_{t}\right) d \Phi_{t} \\
\bar{H}_{t+1} & =\int h_{t+1}\left(y_{t}, h_{t}, k_{t}\right) d \Phi_{t} \\
S_{t} & =\int s_{t}\left(y_{t}, h_{t}, k_{t}\right) d \Phi_{t}
\end{aligned}
$$

5. (Aggregate Law of Motion): ${ }^{16}$

$$
\Phi_{t+1}=\Gamma_{t}\left(\Phi_{t}\right)
$$

A steady-state equilibrium is an equilibrium such that all elements of the equilibrium that are indexed by $t$ are constant over time.

\section{Policy Experiments}

Our benchmark economy has no child labor legislation in place (i.e. $\nu_{t}=\mu_{t}=$ $\left.\tau_{t}=0\right)$. We assume that the economy starts in the steady state equilibrium associated with the absence of child labor legislation. We denote by period $t=1$ this initial steady state. A reform is carried out at the beginning of period $t=2$, and the government is committed to this reform and enforces it perfectly. ${ }^{17}$ The reform is not expected by any household, but once it is carried out, all agents of the economy correctly believe that it stays in place for all time. The three reforms we study are

1. A child labor ban (i.e. $\nu_{t}=1, \mu_{t}=0$ and $\tau_{t}=0$ for all $t \geq 2$ ). Under the new policy parents can no longer have their child work in the market sector for the wage $w_{t}$. Children can still work in the household sector. As there is no publicly financed education, parents must still pay the resource $\operatorname{cost} \kappa$ to send their children to school.

\footnotetext{
${ }^{16}$ The functions $\Gamma_{t}$ can be written explicitly as follows. Define Markov transition functions $Q_{t}: Z \times \mathcal{B}(Z) \rightarrow[0,1]$ induced by the transition probabilities $\pi$ and the optimal policies $h_{t+1}\left(y, h, k ; \Phi_{t}\right)$ and $k_{t+1}\left(y, h, k ; \Phi_{t}\right)$ as$$
Q_{t}((y, h, k),(\mathcal{Y}, \mathcal{A}, \mathcal{C}))=\sum_{y^{\prime} \in \mathcal{Y}}\left\{\begin{array}{c}
\pi\left(y^{\prime} \mid y\right) \text { if } h_{t+1}\left(y, h, k ; \Phi_{t}\right) \in \mathcal{A} \text { and } k_{t+1}\left(y, h, k ; \Phi_{t}\right) \in \mathcal{C} \text { else }
\end{array}\right.
$$

for all $(y, h, k) \in Z$ and all $(\mathcal{Y}, \mathcal{A}, \mathcal{C}) \in \mathcal{B}(Z)$. Then

$$
\Phi_{t+1}(\mathcal{Y}, \mathcal{A}, \mathcal{C})=\left[\Gamma_{t}\left(\Phi_{t}\right)\right](\mathcal{Y}, \mathcal{A}, \mathcal{C})=\int Q_{t}((y, h, k),(\mathcal{Y}, \mathcal{A}, \mathcal{C})) d \Phi_{t}
$$

for all $(\mathcal{Y}, \mathcal{A}, \mathcal{C}) \in \mathcal{B}(Z)$.

${ }^{17}$ This implies that under a child labor ban children cannot work in the market sector (although they may work in the household sector); if an education law requires mandatory schooling, all children go to school. 
2. Provision of public tax-financed education (i.e. $v_{t}=0, \mu_{t}=1$ and $\tau_{t}=$ $\frac{S_{t} \kappa}{w_{t} N_{t}+r_{t} K_{t}}$ for all $t \geq 2$ ). Parents retain complete freedom with respect to the time allocation of their child and have to pay income taxes on all market-generated income (including that from child labor), but can send their children to school free of charge. Note that it still may be suboptimal to do so since school still carries time opportunity costs; thus $S_{t}<1$ is possible. This thought experiment may also represent a situation where a mandatory education law is in place, but it is not enforced. Also note that if this policy leads to universal school attendance, then its allocative and welfare consequences are identical to those of a compulsory schooling law (which includes public financing of school).

3. Adoption of a mandatory schooling law with publicly financed education (i.e. $v_{t}=0, \mu_{t}=1$ and $\tau_{t}=\frac{\kappa}{w_{t} N_{t}+r_{t} K_{t}}$ for all $t \geq 2$ ). The government now provides free schooling to each child, but imposes the restriction $s_{t}=$ $S_{t}=1$. Now mandatory schooling necessarily takes up a portion of the child's time that could have been used for work. By law all children in the population attend school and acquire human capital.

To quantify the welfare effects of different policy reforms, we compute consumption equivalent variation measures for different groups of agents. We ask by what percentage a dynasty's consumption has to be increased, for all time and all contingencies, in the old steady state with no child labor and schooling legislation, in order to be indifferent to a policy reform inducing a transition to the new steady state. Note that this measure explicitly captures welfare along the transition path. If the period utility function is assumed to be of CRRA form with coefficient of relative risk aversion $\sigma$, this welfare measure is given by

$$
E V(y, h, k)=\left(\frac{V_{2}(y, h, k)}{V_{1}(y, h, k)}\right)^{\frac{1}{(1-\sigma)}} .
$$

For example, an $E V(y, h, k)=1.05$ means that a dynasty with characteristics $(y, h, k)$ experiences a welfare gain from a given reform equivalent to receiving $5 \%$ higher consumption for all time and all states in the old steady state.

Similarly, to compare steady state welfare between a regime with no child labor legislation and a regime with such legislation, we compute the consumption equivalent variation of a dynasty about to be born into the new as compared to be born into the old steady state, i.e. under the veil of ignorance, as

$$
E V^{S S}=\left(\frac{\int V_{T}(y, h, k) d \Phi_{T}}{\int V_{1}(y, h, k) d \Phi_{1}}\right)^{\frac{1}{(1-\sigma)}}
$$

where $T$ indexes variables in the new steady state.

\section{Model Calibration}

The model parameters are calibrated so that the initial steady state without child labor legislation replicates selected observations in the U.S. economy dur- 
ing the time before most states adopted such laws ${ }^{18}$. We calibrate to available data from around $1870-80$ for this reason. As individuals live for only two periods in the benchmark version of our model, one model period is interpreted to last 20 years. This is roughly consistent with U.S. data on average life expectancy (conditional on successful survival to age 6 , the age at which we assume children become economically active).

\subsection{Technology}

For the market sector we normalize $A=1$ and set the capital share of income to $\theta=0.34$, the value reported by Williamson and Lindert (1980) for the US in 1871 . The value of the externality parameter $\gamma$ cited in the literature falls in a fairly large interval $\gamma \in[0,0.417]$ where the upper end of the interval is an extreme outlier and stems from Lucas (1988). Borjas (1992) and also Carpena and Santos (2000) find values of 0.18 and 0.15, respectively. Using the lower of these values as benchmark, we conduct sensitivity analysis on gamma to assess how the results change when there is no externality, and as the value of the externality is increased over the range $\gamma \in[0,0.417]$. Finally, the chosen value for depreciation $1-\delta=(1-0.06)^{20}=1-0.71$ is standard in business cycle research, as we do not have reliable data on capital stocks or investment for the U.S. economy before the turn of the century.

The curvature parameter $\alpha$ for the household production function determines the marginal return of household production, relative to market work of children. We choose $\alpha$ such that in the stationary equilibrium of our benchmark economy the average time children spend working in the market sector is $22 \%$ of their non-sleeping, non-leisure time, consistent with Carter and Sutch (1996), who report a labor force participation rate for boys in 1880 of $32 \%$ and for girls of $12 \%$ (and thus an average participation rate of $22 \%$ ). This yields $\alpha=0.12$ and thus strongly decreasing returns to scale in the informal household production sector. $^{19}$

Two parameters $(l, \varphi)$ specify the technology governing human capital accumulation, where $l$ measures the time required to go to school and $\varphi$ measures the returns of human capital to an extra unit of time spent in school. Landes and Solmon (1972) report that in states that had a compulsory schooling law by 1880 a pupil enrolled in a public school attended school 94 days a year on average. The total number of days in a year, excluding Sundays, is $6 * 52=318$ days. Thus children in states that required school attendance on average went to school for $30 \%$ of all working days per year in 1880 . Therefore we choose $l=0.3$ indicating that in the model $30 \%$ of a child's time is spend in school if schooling

\footnotetext{
18 According to the data in Landes and Solmon (1972) the only states that had passed mandatory education legislation before the 1869-70 school year were Massachusetts, which passed a law in 1852 requiring children of ages 8-14 to attend school for 20 weeks each year, and Vermont, which passed a law with the same requirements in 1867.

${ }^{19} \mathrm{It}$ is understood that in a general equilibrium model like ours all parameters affect all equilibrium quantities and prices. In our discussion of the calibration we associate a parameter with that equilibrium entity it affects most, in a quantitative sense.
} 
is chosen by their parents or dictated by the government. ${ }^{20}$ Our choices imply that, if all children go to school, on average a child spends $30 \%$ of the year in school, $22 \%$ working in the market sector and the remaining $48 \%$ working at home. To calibrate $\varphi$, the multiplicative term in the human capital production function, we use the wage premium for education estimated by Acemoglu and Angrist (2000). They find an increase in the wage of approximately $8 \%$ per year of schooling. In states with compulsory schooling laws in 1880 children had to attend school from age eight to fourteen at least (see Landes and Solomon, 1972). With six years of school and the estimated wage premium of $8 \%$ per year a skill premium of $48 \%$ results. Hence $\varphi l=0.48$, and with $l$ calibrated to 0.3 we obtain $\varphi=1.6$.

Finally, school expenditures per child, $\kappa$, are derived from the annual cost of sending a child to school as a percentage of GDP per capita. The total annual expenditure per pupil in 1870 was $\$ 15.55$ in current dollars (U.S. Department of Education, 1997) and GDP per capita was $\$ 170$ in current dollars (U.S. Department of Commerce). Thus we select $\kappa$ so that the per-pupil schooling cost is $9.15 \%$ of GDP per capita in our initial steady state, where GDP in our model is measured as output in the market sector. This requires $\kappa=0.069$.

Table 1 summarizes the calibration of technology parameters.

Table 1: Technology Parameters

\begin{tabular}{|c|c|c|c|c|c|c|c|}
\hline$A$ & $\theta$ & $\gamma$ & $\delta$ & $\alpha$ & $l$ & $\varphi$ & $\kappa$ \\
\hline 1.0 & 0.34 & 0.15 & $6 \%$ p.a. & 0.12 & 0.3 & 1.6 & 0.069 \\
\hline
\end{tabular}

\subsection{Preferences and Endowments}

We assume that the period utility function of an adult is of Constant Relative Risk Aversion (CRRA) form, $u(c)=\frac{c^{1-\sigma}}{1-\sigma}$. We choose a coefficient of relative risk aversion $\sigma=2$, well within the values usually employed for business cycle and public finance studies. The time discount factor $\beta$ is chosen so that the annual risk free real interest rate, $r$, in the initial steady state is equal to $2 \%$. This implies $\beta=(0.979)^{20}$.

We specify the stochastic component of adult labor productivity as a symmetric two-state Markov process. Hence the parameters to calibrate are the states of the income process, $y_{l}$ and $y_{h}$ and the conditional probability that children, once adults, remain at the same productivity level as their parents, $\pi$. We use data on the spread of wages within an education group and intergenerational persistence of income to pin down $y_{h}, y_{l}$, and $\pi$. Williamson and Lindert (1980), in studying intra-sectoral wage differentials for common laborers in 1850, suggest a wage differential within an educational group of around $60 \%$. Normalizing $E(y)=1$ and choosing $y_{l}, y_{h}$ such that $\frac{y_{h}}{y_{l}}=1.6$ yields values

\footnotetext{
${ }^{20}$ Implicit in this choice is the assumption that school, including the sometimes long commute to and from school, takes up the entire non-sleeping, non-leisure time of a day. In addition, our assumption of two periods of life, one spent as child, may overstate the time commitment needed for school, but is necessary to justify the fact that economic decisions are taken only in the second period of life.
} 
(exploiting the symmetry of the Markov chain ${ }^{21}$ ) of $y_{l}=0.769$ and $y_{h}=1.231$. Solon (1992) and Zimmerman (1992) estimate the elasticity of a son's income with respect to his father's income at 0.4 . This provides an estimate of persistence. Since, conditional on same education, a lucky parent is $60 \%$ richer than an unlucky parent, this number implies that, on average, children of lucky parents should be $24 \%$ richer than children of unlucky parents. We have

$$
\begin{aligned}
& E\left(y^{\prime} \mid y=y_{l}\right)=\pi y_{l}+(1-\pi) y_{h} \\
& E\left(y^{\prime} \mid y=y_{h}\right)=\pi y_{h}+(1-\pi) y_{l}
\end{aligned}
$$

and thus

$$
\frac{E\left(y^{\prime} \mid y=y_{h}\right)}{E\left(y^{\prime} \mid y=y_{l}\right)}=\frac{\pi y_{h}+(1-\pi) y_{l}}{\pi y_{l}+(1-\pi) y_{h}}=1.24
$$

which yields, conditional on the calibrated values for $y_{l}$ and $y_{h}$, a $\pi=0.732$.

Finally we have to specify the productivity of a child, relative to that of an adult, $y_{c}$. Goldin (1979) documents that in Philadelphia in 1880, in a typical native white American family with father of age 40-44, roughly $11 \%$ of all income was derived from child labor. Assuming the same number of children as adults in such a family ${ }^{22}$ and using our earlier target of $22 \%$ of children's time used in market production we find $y_{c}=0.45$ necessary to reproduce the child labor income statistic. ${ }^{23}$ We summarize our parameter choices governing preferences and endowments in Table 2.

Table 2: Preference and Endowment Parameters

\begin{tabular}{|c|c|c|c|c|c|}
\hline$\beta$ & $\sigma$ & $y_{h}$ & $y_{l}$ & $\pi$ & $y_{c}$ \\
\hline$(0.979)^{20}$ & 2.0 & 1.231 & 0.769 & 0.732 & 0.45 \\
\hline
\end{tabular}

\section{Results}

All of the policy experiments that we consider start with an initial steady state with no child labor legislation and end in a final steady state with a child labor ban or tax-financed free (compulsory or voluntary) education. We first discuss the properties of the steady state equilibria under these different policies and then discuss the transition dynamics and welfare consequences induced by the various policy reforms. Finally, we perform an extensive sensitivity analysis of our results with respect to changes in crucial parameters and modelling assumptions.

\footnotetext{
${ }^{21}$ This symmetry implies that the unique invariant measure associated with the Markov transition matrix puts $50 \%$ probability on both states. The expectation of income is with respect to this probability measure.

22 This is of course true by construction in our model, but also approximately true in Goldin's (1979) data, with 2.037 children present, on average, in a family with the same characteristics.

${ }^{23}$ We solved

$$
\frac{0.22 y_{c} w}{\left(1+0.22 y_{c}\right) w}=0.11
$$

for $y_{c}$, using the fact that average adult productivity is 1 and adults work in the market sector all their discretionary time.
} 


\subsection{Steady State}

Table 3 summarizes the values of model variables under a child labor ban, free education, and free but mandatory education. For all steady states with child labor legislation we compute the percentage change of a particular variable with respect to the initial steady state with no legislation in place (with the exception of $r_{p a}, \bar{m}, \bar{s}, G i(k)$ and $\left.E V^{S S}\right)$. Here $r_{p a}$ is the annualized interest rate, $Y$ is output in the market sector, $H$ is the stock of human capital, $\bar{m}$ is the average time spent by children in the formal sector, $\bar{s}$ is the fraction of all children going to school, and $G i(k)$ is the Gini coefficient of asset holdings. ${ }^{24}$

Table 3. Steady State Results

\begin{tabular}{|c|c|c|c|c|c|c|c|c|c|c|}
\hline & $r_{p a}$ & $w$ & $Y$ & $K / Y$ & $H$ & $N$ & $\bar{m}$ & $\bar{s}$ & $G i(k)$ & $E V^{s s}$ \\
\hline \hline Initial SS & $2 \%$ & 0.363 & 0.749 & 5.69 & 1.24 & 1.364 & $22 \%$ & $50 \%$ & 0.56 & \\
\hline Ch. L. Ban & $1.99 \%$ & $0.13 \%$ & $-7.0 \%$ & $0.2 \%$ & $0 \%$ & $-7.2 \%$ & $0 \%$ & $50 \%$ & 0.56 & $-0.94 \%$ \\
\hline Free Educ. & $2.18 \%$ & $1.77 \%$ & $10.4 \%$ & $-4.3 \%$ & $19.4 \%$ & $8.5 \%$ & $0 \%$ & $100 \%$ & 0.55 & $3.26 \%$ \\
\hline Man. Educ. & $2.18 \%$ & $1.77 \%$ & $10.4 \%$ & $-4.3 \%$ & $19.4 \%$ & $8.5 \%$ & $0 \%$ & $100 \%$ & 0.55 & $3.26 \%$ \\
\hline
\end{tabular}

\subsubsection{Child Labor Ban}

Comparing the no-policy steady state to the steady state with a ban on child labor in the market sector, we observe that labor supply in the market sector declines and production in the household sector increases significantly. This is because children who formerly worked in the market sector now spend part of their former market time (apart from going to school) working in the household sector. This reallocation of child labor increases the real wage of adult workers in the market sector and drives down the interest rate. The changes in both prices are modest, however, since not only labor supply, but also the supply of capital falls (this can be deduced from the table by observing that the capital-output ratio is roughly unchanged and output falls significantly). As both production inputs decline substantially, so does output. Why does capital accumulation drop with a ban on child labor in the formal sector? Families, in particular poor ones (those with a low $y$-shock) are now forced to make their children work exclusively in the informal sector, which is very unproductive at the margin. The loss in family income is compensated in part by lower savings and thus a lower capital stock available for production in equilibrium.

Most important for our purposes is the effect of the legislative change on the individual education decision. As evident from the table, the policy is not successful in inducing more families to send their children to school. With and without child labor ban all households with currently good productivity shocks send their children to school and those with bad shocks do not, partially because of the direct cost of schooling, partially because of the opportunity cost of a child's time. Simply reducing this opportunity cost by making child labor

\footnotetext{
${ }^{24}$ Since $Y$ is a flow variable and $K$ a stock variable, in our measurement of the capitaloutput ratio we divided $Y$ by the period length, 20 years, to make our numbers comparable to capital-output ratios in yearly models.
} 
in the formal sector illegal is insufficient to induce school attendance of children from poor families, it merely robs these families of the ability to use child labor in the formal sector as insurance against bad parental productivity shocks and thus makes poor families even poorer. ${ }^{25}$ Consequently, a ban of child labor, when not coupled with any law further encouraging school attendance, leads to welfare losses in our benchmark model. The size of these losses are nontrivial; the steady state equivalent variation amounts to $-0.94 \%$, indicating that one could lower steady state consumption, for any individual state and for all time, by $0.94 \%$ in the initial steady state and still have a dynasty ex ante indifferent between being born into the old and the new steady state which child labor ban.

\subsubsection{Education Policies}

All our education policies contain a public provision of schooling, financed by a proportional income tax. In addition, school attendance may be stipulated by a compulsory schooling law or may be left to the decision of the parents. As mentioned above, if the unconstrained decisions of households yield universal school attendance, then the introduction of a compulsory schooling law does not change allocations or welfare. As is evident from table 3, with tax financed free education all families send their children to school, and thus the ensuing stationary equilibrium is identical to that under tax-financed mandatory schooling. Therefore, from now on we will limit our discussion of education policies to the tax-financed free schooling policy, unless compulsory schooling laws give rise to different allocations.

Under our benchmark calibration, giving households access to free education induces all families to send their children to school. Consequently in the stationary equilibrium all adults are educated, with aggregate human capital amounting to $H=\bar{H}_{\max }=1+\varphi l=1.48$, a $19 \%$ increase over the initial steady state in which only half of the population (those whose parents where highly productive) was educated, so that $H=1+0.5 \varphi l=1.24$. As a result aggregate labor input $N$ and thus output in the formal sector increases, the real wage declines and the interest rate increases (as the capital-labor ratio declines). However, since children substitute schooling and informal activity for work in the formal sector (partially because of the decline in the real wage), the increase in formal sector labor supply is smaller, in equilibrium, than the increase in adult human capital. In fact, the reduction in the real wage is substantial enough that households opt not to send their children to work in the formal sector, even though there is no legal restriction preventing them from doing so.

Apart from leading to growth in economic activity due to increased human capital accumulation, the education policy contains an important redistributive component, since taxes to finance education are proportional to a households' income, whereas the benefits (saving the schooling cost $\kappa$ ) are independent across incomes. This redistribution between households that differ in their labor productivity ex post provides insurance against bad productivity shocks ex-ante,

\footnotetext{
${ }^{25}$ At the margin, a child that does not go to school could, if permitted, earn a wage in the formal sector that is about $33 \%$ higher than its marginal product in the informal sector.
} 
and thus is a welcome partial substitute to private labor income insurance markets, which are absent in our model by construction. While the increased level of human capital and thus production and consumption is mainly responsible for the sizeable welfare gains of $3.3 \%$ in consumption equivalent variation, the insurance aspect of the education policy contributes to its size. A side effect of the redistributional features of the education policy is a small reduction in wealth inequality due to the introduction of free schooling; the Gini coefficient of wealth declines close to one percentage point in the new, as compared to the pre-policy steady state.

\subsubsection{A Combination of Policies}

In the baseline calibration of our model, with free (or mandatory) education all households send their children to school and no household finds it optimal to make them work in the formal sector. Thus, adding a child labor ban to such an education policy introduces a nonbinding constraint; the resulting allocations are thus identical to those arising in a steady state with education policy only. For the remainder of this paper we therefore do not report results for a combination of education and child labor legislation, unless the results differ from the case of education policies only. ${ }^{26}$

\subsection{Transition Dynamics and Welfare Implications}

The allocation and welfare analysis so far has compared steady states under different policies, including the laissez-faire economy. We now discuss the dynamic transition induced by a sudden, unexpected policy reform. Our main focus is the growth path of the main macroeconomic aggregates as well as the distribution of welfare gains/losses across the population. As we will see, the steady state welfare numbers reported in the previous section may, for some groups substantially, overstate the welfare gains from an education reform and understate the welfare losses from a ban of child labor in the formal sector.

\subsubsection{Child Labor Ban}

The steady state analysis indicated a reduction in market production, a small increase in real wages and no change of human capital in response to the introduction of a child labor law in the market sector. In addition, steady state welfare declined by about $1 \%$ in steady state consumption, from an ex-ante point of view.

From figure 1 we observe that, before settling down to their new steady state values, macroeconomic variables follow a nontrivial transition path, the dynamics of which helps to explain the welfare results obtained below. In this figure, period 0 represents the old steady state and period 1 represents the first

\footnotetext{
${ }^{26}$ These differences arise only if with education policies alone either not all households send their children to school or some households still opt to have their children work part-time in the formal sector.
} 


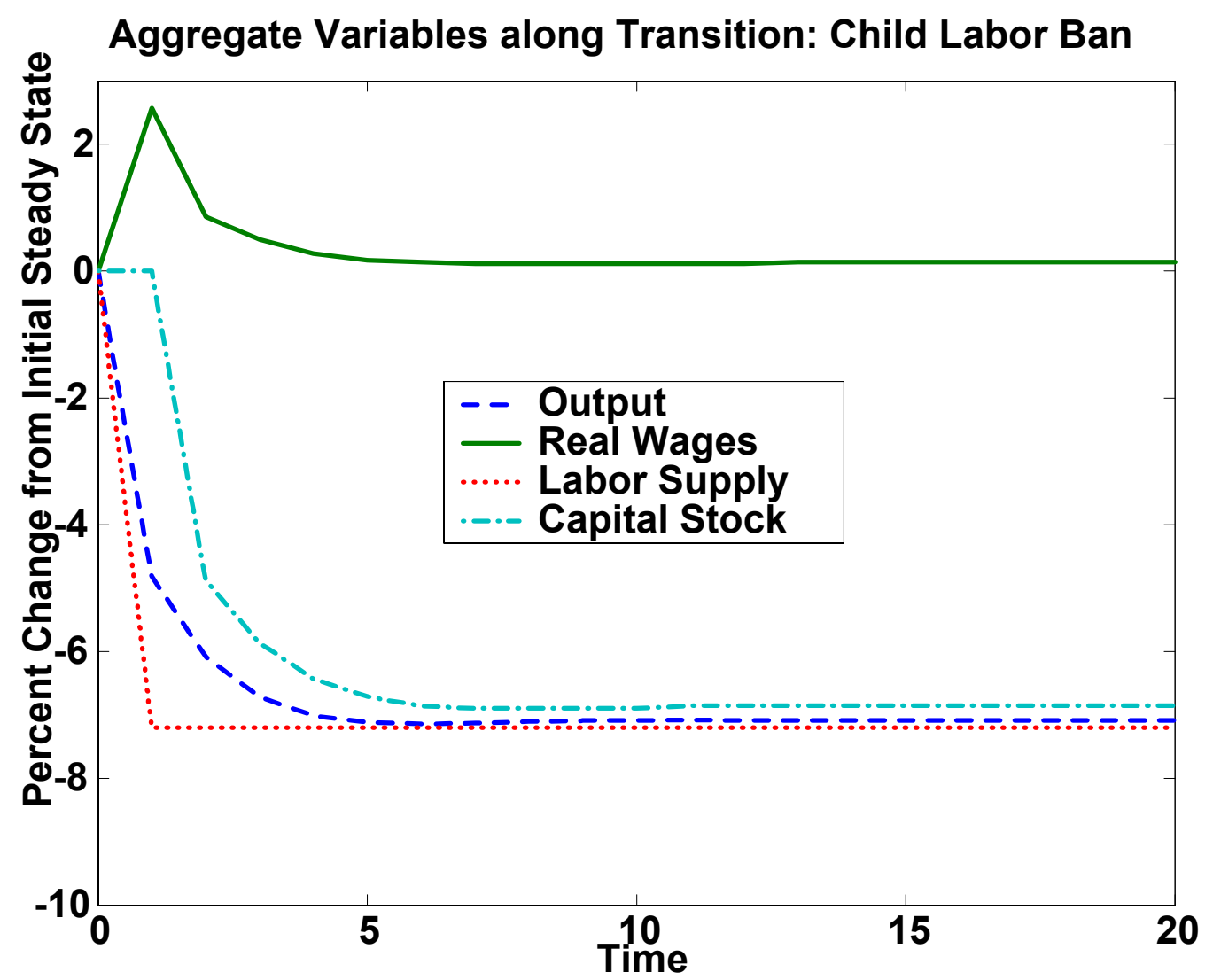

Figure 1: Transition Path: Child Labor Law

model period after the unanticipated reform was enacted. Thus by construction physical and human capital (the latter not shown) remain at their old steady state values in period 1 (because these variables are predetermined from the previous period). As child labor in the formal sector declines, due to the forced substitution into the informal sector, so does labor supply in period 1. Since capital is predetermined in period 1 , the large initial decline in labor supply induces a substantial increase in the capital-labor ratio and thus a large increase of the real wage on impact (and a consequent decline in the real interest rate). As capital accumulation also starts to decline, the real wage falls towards its new steady state, which is slightly above its old steady state. It is crucial for the welfare numbers to remember that, although the increase in real wages is modest when comparing steady states, along the transition substantial real wage increases persist for several model periods. Finally, the dynamics of output in the formal sector follows that of labor and capital (since aggregate human 
capital remains constant throughout the transition, because schooling choices do not change); we observe a fast decline of output towards its new, $7 \%$ lower steady state value.

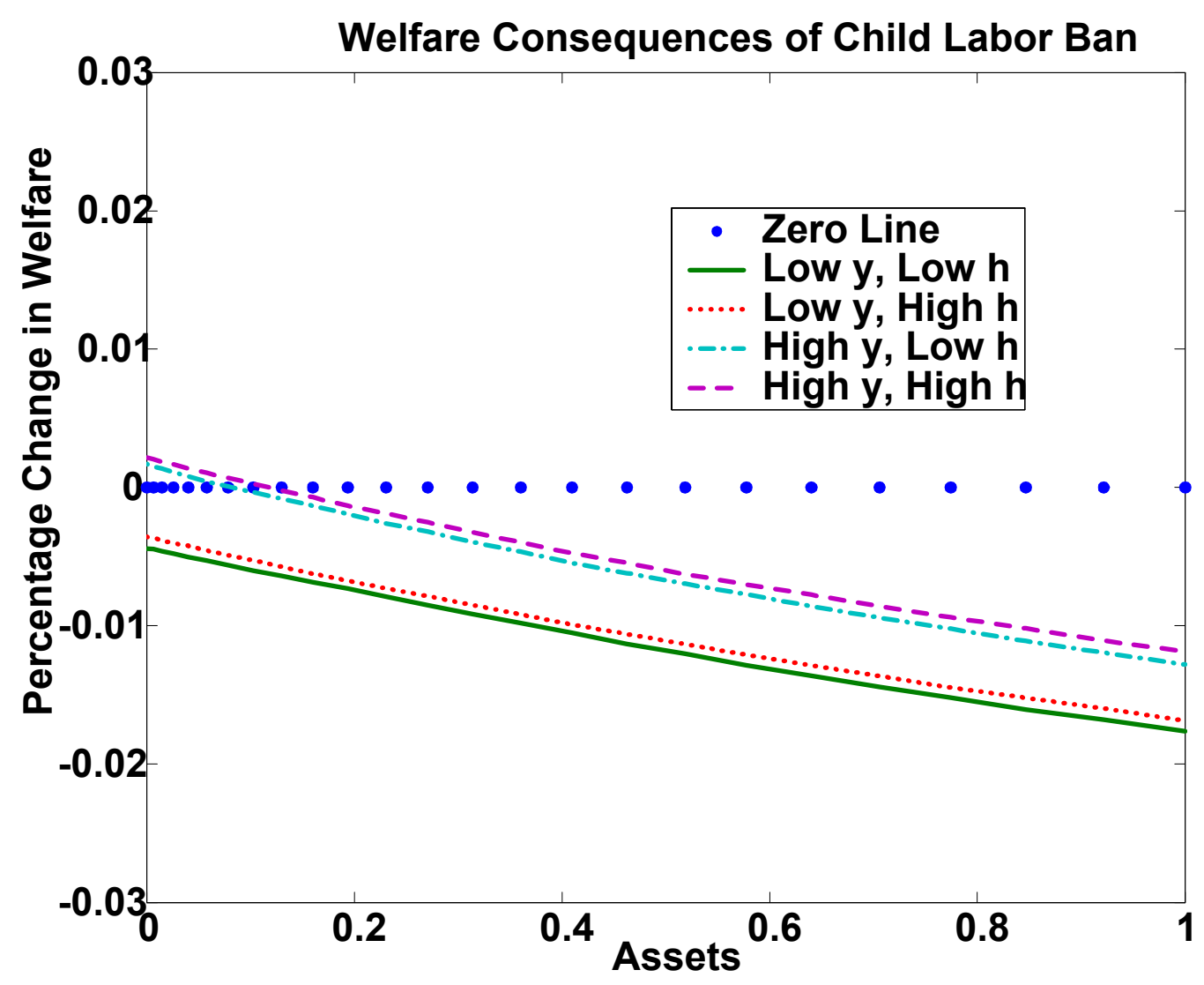

Figure 2: Welfare Consequences of Child Labor Ban

In figure 2 we show the welfare losses of different groups of the population, measured by consumption equivalent variation. We observe that the only population group that would benefit from a ban of child labor in the formal sector are households with currently high parental labor productivity and no financial assets. ${ }^{27}$ These households derive all their income from parental work in the

\footnotetext{
${ }^{27}$ The impact of the state variables $(y, h)$ on welfare differs in a subtle way. High current productivity $y$ and high current human capital $h$ increase current income, although the spread in wages induced by productivity differences $\frac{y_{h}}{y_{l}}=1.6$ is higher than that between human capital differences (which, by calibration, equals 1.48). Furthermore the process for $y$ features persistence, whereas human capital dies with the parent and needs to be newly acquired by the child. This implies that currently and persistently high wages benefit households with currently high productivity to a larger extent than households with highly educated parents.
} 
market sector, send their children to school and let them work in the informal sector after school. The reform induces a strong increase in the parental wage (declining over time, however) and does not distort the child's time allocation for these households. It is also evident that, ceteris paribus, the higher a households' financial assets, the larger the welfare losses from a child labor ban. This is due to the fact that a reduction in the real interest rate, substantial at the time of adoption of the reform, reduces the return on those households' (the capitalists) assets. Households with low labor productivity (those one may term the "poor" if they don't possess assets) also stand to lose from ban on child labor, because, even though the parental real wage increases, these households found it optimal to send their children to work in the formal sector to stabilize family income and are now prohibited from doing so. In terms of household income and welfare, the latter negative effect dominates. Thus our empirical model prediction is that capitalists and low-productivity workers lose from a child labor ban, whereas high-productivity workers with little capital income are set to gain. To the extent that these welfare consequences determine opposition and support for such a reform, our model predicts that capitalists and, to a lesser extent, the income-poor oppose child labor bans, while supporters should be found mainly among workers with well-paid jobs.

Our model determines the fraction of agents with particular characteristics endogenously in any given point of time. Hence figure 2 has to be "weighted" by the initial steady state distribution over types $(y, h, k)$, in order to determine the fraction of the population that would benefit from a transition of an economy without child labor legislation to an economy with a child labor ban. We find that only about $20 \%$ of the population would prefer to adopt a child labor ban ${ }^{28}$, namely exactly the high-wage families with no financial assets that benefit most from the (mostly temporary) increases in the real wage. It is also interesting to note that most other households' welfare losses from the reform are smaller than the $0.94 \%$ in the steady state. The transition takes time, the decline in output and thus consumption does not occur immediately and real wages rise substantially on impact, so that the steady state welfare losses overstate the true (still substantial) welfare costs from the reform. Thus, in order to derive reliable welfare numbers for the application at hand, it is crucial to compute and analyze the transition dynamics of the economy explicitly. That steady state welfare comparisons can be quite misleading will become even more apparent

\footnotetext{
${ }^{28}$ There is an obvious, albeit very restrictive, sense in which our results can be interpreted as a political economic equilibrium. If the following conditions are met then the fraction of agents with welfare gains from a reform can be interpreted as the fraction of agents voting for the reform. First, a potential reform is voted upon -against the status quo- only once. Second, the reform, once approved, cannot be reversed. Third, all households vote sincerely for the policy yielding higher welfare. Finally, fourth, all households understand that there is one, and only one vote about a reform. Under this interpretation a fraction of agents with welfare gains of more than $50 \%$ indicates that the reform is approved under a simple majority rule. Since there is no repeated voting and thus no startegic or dynamic aspects to the voting decision, nor does the analysis explain why these reform enter the political agenda, we do not want to stress this interpretation. For an explicit voting model of child labor legislation, see Doepke and Zilibotti (2003).
} 
in our study of education policies, to which we turn next.

\subsubsection{Education Policies}

The steady state allocative and welfare consequences of a free schooling law (coupled or not with the legal requirement to attend school) differ substantially, in a positive way, from a child labor ban. Figure 3 shows that the transition dynamics of factor prices and allocations are qualitatively different from the previous reform as well.

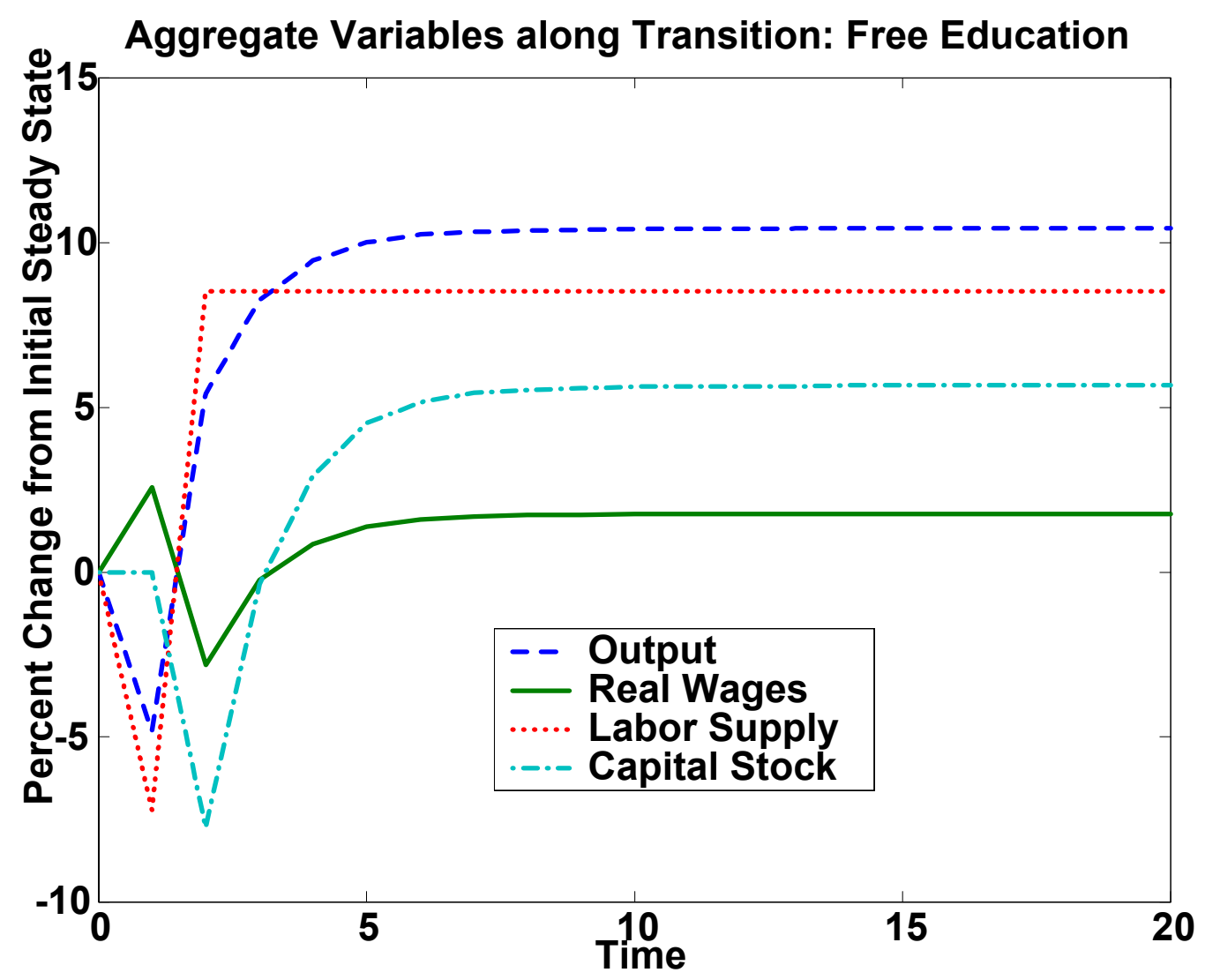

Figure 3: Transition Path: Free Education

As before, in the first period after the reform labor supply in the formal sector declines because children substitute school (rather than informal sector work) for market work. Since human and physical capital stocks are predetermined, output declines and the real wage jumps up. But now, very much in contrast to a child labor ban, the higher school attendance leads to an increase in human 
capital of adults from period 2 onwards, thus an increase in effective labor supply and in output. In this sense human capital, via the endogenous education decision and fueled by educational reform, is the engine of growth in economic activity. Since our model stems from the class of exogenous growth models, this human-capital accumulation induced growth is necessarily temporary and the economy, over time, converges to its new steady state. The dynamics of the capital stock and real wages documented in figure 3 is more subtle. Directly after the reform all households (instead of only a selected group of them) send their children to school, roughly doubling the income tax to finance schools, leading households to save less and thus reducing the capital stock in the second period of the reform. The decline in capital, together with the increase in labor supply, fosters a decline in real wages below the initial steady state level. After the second period, the increase in human capital induces higher wages and thus labor earnings, increased savings, a recovery of the capital stock and thus the real wage converges towards its new, higher steady state level. ${ }^{29}$

The welfare consequences of a transition to publicly financed education are summarized in figure 4. We observe that, ceteris paribus, households with low human capital and with little financial assets benefit most from the reform. Before the reform households with low human capital did not send their children to school, mainly because it was too costly (in terms of resources and in terms of forgone child labor income). Now education is free, which amounts to a large subsidy for this group of the population, given that it now takes advantage of the schooling opportunity and pays moderate income taxes for it (since taxes are proportional and income of these families is low).

Since wages increase more substantially than interest rates, those households that derive a larger fraction of their income from wages, rather than capital, have higher welfare gains, other things equal, which explains why welfare improvements from the reform are declining with assets. The fact that they become negative for large asset holdings is explained by the fact that these households send their children to school even before the reform, labor income is unimportant for them and the income tax for free schools reduces their after tax income by more than the cost of schooling and the moderate gains from rising interest rates (which only becomes effective in period 2 after the reform).

One remarkable feature of figure 4 is the observation that welfare gains for all groups, although sizeable, are bounded below $1 \%$ of consumption, substantially lower than the reported steady state gains of $3.3 \%$. The reason behind these seemingly contradictory results is the change of the cross-sectional distribution over household types between steady states. In the old steady state, at the starting point of the transition, $50 \%$ of all household are without an education and thus have low human capital. In the new steady state all households obtain an education. The steady state welfare gains only capture two effects, the improvement in welfare of a given type in the long run, and the shift towards types with higher welfare. But obtaining education is costly and takes time, the

\footnotetext{
${ }^{29}$ In addition, as the economy grows, so does the tax base, and thus the income tax rate required to finance schooling expenditures declines.
} 


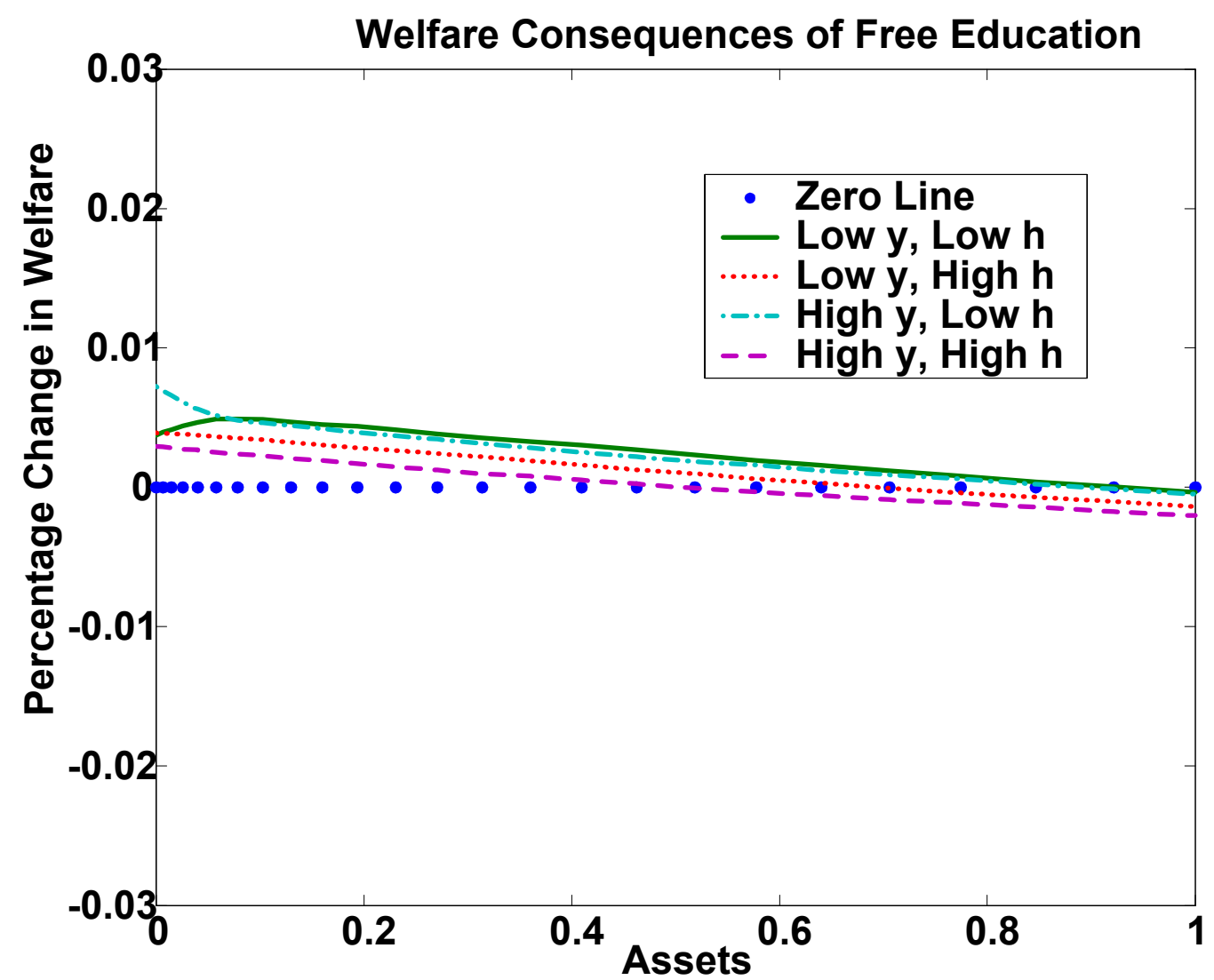

Figure 4: Welfare Consequences: Free Education

steady state welfare numbers grossly overstate the still sizeable benefits from the reform, a finding which cannot be derived and quantified without explicit consideration of the transition path induced by the reform. Finally, $93 \%$ of all households benefit from the reform of introducing free, tax financed education (all but the richest capitalists).

\subsection{Sensitivity Analysis}

\subsubsection{The Size of the Externality}

The steady state and transition results outlined above are derived from the model, under a particular calibration described in detail in Section 6. One crucial and controversial model parameter is the human capital externality, which we set to $\gamma=0.15$. We conducted sensitivity analysis for the range $\gamma \in[0,0.417]$, the set of empirical estimates we are aware of, to determine how a weaker or 
stronger human capital externality would affect our results. The human capital externality is one of the reasons that child labor legislation has potentially positive welfare effects in our model. But even in its absence, policy interventions may be called for to offset the inability of households to write contracts contingent on idiosyncratic income shocks and, more importantly, to borrow against their children's income. Hence, although weakening the externality will weaken positive the welfare effects for child labor legislation, it is not clear a priori that even eliminating the human capital externality altogether will result in negative welfare effects. Table 4 summarizes our results.

\begin{tabular}{l|r|r|r|r|r|r}
\multicolumn{8}{c}{ Table 4: Sensitivity of Results to Human Capital Externality } \\
& \multicolumn{2}{|c|}{$\gamma=0$} & \multicolumn{2}{|c}{$\gamma=0.15$} & \multicolumn{2}{c}{$\gamma=0.417$} \\
Variable & \multicolumn{1}{|c|}{ Ban } & Educ. & Ban & Educ. & \multicolumn{1}{c}{ Ban } & Educ. \\
\hline \hline$\% \Delta$ in $w$ & $0.14 \%$ & -2.46 & $0.13 \%$ & $1.77 \%$ & $12.18 \%$ & $9.85 \%$ \\
$\% \Delta$ in $Y$ & $-4.96 \%$ & $8.23 \%$ & $-7.06 \%$ & $10.42 \%$ & $19.33 \%$ & $21.55 \%$ \\
$\% \Delta$ in $H$ & $1.39 \%$ & $21.01 \%$ & $0 \%$ & $19.35 \%$ & $19.35 \%$ & $19.35 \%$ \\
$E V^{S S}$ & $-0.47 \%$ & $1.61 \%$ & $-0.94 \%$ & $3.26 \%$ & $7.48 \%$ & $7.74 \%$ \\
$\%$ Benef. & $21.5 \%$ & $0 \%$ & $20.4 \%$ & $93.1 \%$ & $100 \%$ & $100 \%$
\end{tabular}

The results are not surprising, for the most part. A higher externality strengthens the increase of wages, output and human capital accumulation due to child labor and education reforms and leads to more favorable welfare consequences from enacting the reform. With a bigger externality a households' wage depends more strongly on the economy-wide average human capital; consequently any policy that is successful in increasing that average will benefit those whose income is mostly derived from labor. The table also shows that, qualitatively, the assessment about the desirability and implementability of both types of reforms changes as the size of the externality changes. Our results for $\gamma=0$ lead us to conclude that credit market frictions alone (the absence of insurance markets and the inability of households to borrow against future labor income of their children to pay for their education) are not sufficient to make the case, on normative grounds, for the existence of child labor and education policies of the kind studied in this paper. ${ }^{30}$

\subsubsection{Relaxation of Borrowing Constraints}

One of the premier reasons in our model to expect under-investment in human capital, besides the human capital externality, is the inability of households to borrow against their children's earnings to finance their education. In this subsection we relax this assumption; in particular we now permit households to

\footnotetext{
${ }^{30}$ Some details for the results deserve further comment. First, the finding that human capital increases with a child labor ban for $\gamma=0$, but not for $\gamma=0.15$ is due to the fact that human capital accumulation is lower in the steady state without policy for $\gamma=0$ to start with. Second, for $\gamma=0.417$ the results obtained for a combination of both policies do not coincide with those fore ducation policies only, because for the latter policy children continue to work in the formal sector after the reform. The additional child labor restriction is thus an occationally binding constraint, which leads to lower labor supply and welfare gains.
} 
borrow up to a generous amount equal to the entire lifetime wage of an adult with low human capital and low productivity shock. While we believe that our previous assumption preventing borrowing altogether is a better approximation of reality, the results derived under the new, relaxed constraint will allow us to assess the relative quantitative importance of externalities and borrowing constraints as a rationale for child labor and education laws. All parameters are re-calibrated to deliver the same empirical targets as before.

Table 5: Steady State Results with Relaxed Borrowing Constraint

\begin{tabular}{|c|c|c|c|c|c|c|c|c|c|}
\hline & $r_{p a}$ & $w$ & $Y$ & $H$ & $N$ & $\bar{m}$ & $\bar{s}$ & $E V^{s s}$ & $\%$ Ben. \\
\hline \hline Initial SS & $2 \%$ & 0.362 & 0.75 & 1.24 & 1.364 & $22 \%$ & $50 \%$ & & \\
\hline Ch. L. Ban & $2 \%$ & $0.06 \%$ & $-7.1 \%$ & $0 \%$ & $-7.2 \%$ & $0 \%$ & $50 \%$ & $-0.9 \%$ & $35.1 \%$ \\
\hline Free Educ. & $2.19 \%$ & $1.77 \%$ & $10.5 \%$ & $19.4 \%$ & $8.5 \%$ & $0 \%$ & $100 \%$ & $3.61 \%$ & $86.5 \%$ \\
\hline
\end{tabular}

Table 5 shows that the relaxation of the borrowing constraint leaves the result qualitatively, and for the most part quantitatively, unchanged. The borrowing limit is loose enough for households to borrow the entire cost of schooling for their children (in fact, it allows borrowing of roughly three times that cost). Thus one may expect the households that previously (under the strict constraint and without policy) did not send their children to school now change their mind. They do not. These are households with currently low labor productivity; given that the Markov process is mean-reverting in expectation their children are more productive and will have better lives, conditional on the same level of education. Thus these households would like to bring consumption of the dynasty forward, rather than postpone it by making a human capital investment. This becomes apparent when noting that these households do borrow, once allowed to, however, not for schooling expenses of their children, but rather for higher current consumption.

The fact that the asset distribution becomes more dispersed (a significant fraction of households incurs debt, and more asset-rich people issuing that debt emerge) also explains why the percentage of households benefitting from an education law slips, compared to the benchmark economy. While the welfare consequences, conditional on the same state $(y, h, k)$, remain roughly the same, the presence of more asset-rich people in the stationary distribution opposed to the education law decreases the constituency for such a reform. On the other hand, more households now favor child labor bans as the stationary distribution features more asset-poor households.

\subsubsection{Stochastic Child Labor Productivity}

So far we have treated child labor productivity $y^{c}$ as a deterministic parameter, making child labor an effective tool to insure adult labor productivity shocks. Now we relax this assumption and allow child labor productivity to be stochastic as well, following a discrete-state Markov chain with support $Y^{c}=\left\{y_{l}^{c}, y_{m}^{c}, y_{h}^{c}\right\}$ and transition probabilities for the productivity of the family $\left(y, y^{c}\right)$ given by $\pi\left(y^{\prime}, y^{c \prime} \mid y, y^{c}\right)$. 
Productivity or wages differentials among child workers are hard to find for the U.S. around 1880. We have data, however, for wage differentials between boys and girls working in the market sector. Thus we interpret the randomness of child wages as deriving from the random sex of the child. A family is assumed to be composed of two adults and two children, which are both male with probability 0.25 , both female with the same probability and with probability 0.5 are of mixed sex. As adults, these agents form marriages, with wages determined by the main breadwinner of the family. These assumptions imply that the productivity of the children in the household is uncorrelated with that of adults (although adult productivity is still correlated with the productivity of parents, as before). Thus $\pi\left(y^{\prime}, y^{c \prime} \mid y, y^{c}\right)=\pi\left(y^{\prime} \mid y\right) \pi\left(y^{c \prime}\right)$. If we let $y_{b o y}^{c}$ denote the relative wage of a boy and $y_{\text {girl }}^{c}$ that of a girl, the states and probabilities of child labor productivity are

Table 6: Stochastic Child Labor Productivity

\begin{tabular}{l|l|l} 
State & Value & $\pi\left(y^{c}\right)$ \\
\hline$y_{l}^{c}$ & $y_{\text {girl }}^{c}$ & 0.25 \\
$y_{m}^{c}$ & $\frac{y_{\text {boy }}+y_{\text {girl }}^{c}}{2}$ & 0.5 \\
$y_{h}^{c}$ & $y_{\text {boy }}^{c}$ & 0.25
\end{tabular}

Goldin (1979) documents that for American white families in Philadelphia in 1880 the average family size was roughly 4.3 (suggesting that the assumption of two children per family is a good approximation) and that wages of girls of age 10 were roughly $86 \%$ of that of boys. Remembering from above that average child productivity, relative to average adult productivity equals 0.45 , we choose

$$
y_{\text {girl }}^{c}=\frac{0.45 * 0.86}{1+0.86} \text { and } y_{\text {boy }}^{c}=\frac{0.45 * 1}{1+0.86} .
$$

This choice implies significant child labor productivity uncertainty, of slightly smaller size than adult labor productivity uncertainty. All predetermined parameters are kept the same, the remaining ones are re-calibrated so that the economy with stochastic child labor attains the same empirical targets as the benchmark economy.

Table 7: Steady State Results with Stochastic Child Labor Productivity

\begin{tabular}{|c|c|c|c|c|c|c|c|c|c|}
\hline & $r_{p a}$ & $w$ & $Y$ & $H$ & $N$ & $\bar{m}$ & $\bar{s}$ & $E V^{s s}$ & $\%$ Ben. \\
\hline \hline Initial SS & $2 \%$ & 0.362 & 0.75 & 1.237 & 1.366 & $22 \%$ & $49.4 \%$ & & \\
\hline Ch. L. Ban & $1.99 \%$ & $0.22 \%$ & $-7.2 \%$ & $0.3 \%$ & $-7.34 \%$ & $0 \%$ & $50 \%$ & $-0.93 \%$ & $19.2 \%$ \\
\hline Free Educ. & $2.18 \%$ & $1.88 \%$ & $11.1 \%$ & $19.7 \%$ & $9.06 \%$ & $2 \%$ & $100 \%$ & $3.37 \%$ & $94.7 \%$ \\
\hline
\end{tabular}

Since the dynamic programming problem for a given household as well as the equilibrium conditions remain almost unchanged we omit their repetition. Table 7 instead summarizes the results from our sensitivity analysis, documenting that the findings are almost identical to the benchmark economy. The only significant difference from our previous results is some heterogeneity of families with respect to the time allocation of children. Families with boys, other things equal, send 
their children to work longer hours in the formal sector, whereas girls work longer hours in the informal sector, consistent with the historical U.S. evidence as well as stylized facts from currently developing countries.

\subsubsection{Transfers to Elder Members of the Household}

The U.S. around 1880 did not have a social security system (it was introduced in 1935). Thus older individuals often had to rely on intra-family transfers for old-age consumption. In order to account for this phenomenon we modify our model to include a third period of life. The first two periods of life remain the same, but in the third period agents consume resources given to them by their children. Let $c_{2}$ denote this consumption, assumed to be a fixed fraction $\xi$ of the gross income of their children, and let $\chi>0$ denote the discount factor between the second and the third period of an individuals' life. The dynamic programming problem now reads as (without child labor legislation and stochastic child productivity)

$$
V(y, h, k ; \Phi)=\max _{c_{1}, m, n, s, h^{\prime}, k^{\prime}}\left[u\left(c_{1}\right)+\sum_{y^{\prime}} \pi\left(y^{\prime} \mid y\right)\left\{\chi u\left(c_{2}^{\prime}\right)+\beta V\left(y^{\prime}, h^{\prime}, k^{\prime} ; \Phi^{\prime}\right)\right\}\right]
$$

subject to

$$
\begin{aligned}
c_{2}^{\prime}\left(y^{\prime}, h^{\prime}, k^{\prime}\right) & =\xi\left[\left(y^{\prime} h^{\prime} w^{\prime}+\left(1+r^{\prime}\right) k^{\prime}\right]\right. \\
c_{1}+\kappa s+k^{\prime}+c_{2}(y, h, k) & \leq\left(y h+y^{c} m\right) w_{t}+\left(1+r_{t}\right) k+f\left(y^{c} n\right)
\end{aligned}
$$

as well as the time constraint for child labor and the law of motion for human capital. Note that the amount of consumption provided to parents in old age is not a choice variable, but rather a matter of social convention, as measured by $\xi$. Without altruism towards the elderly, the optimal transfer to an old individual is 0 . Also note that, given this formulation, a current adult can, by educating her child and/or leaving her financial assets, positively impact her own consumption when old.

The additional parameters that need to by chosen for this extension are $\xi$ and $\chi$. To insure comparability with our previous results we keep the time discount factor $\beta$ at its benchmark economy level of 0.979 (per annum) and jointly choose $\chi=0.1655$ and $\xi=0.614$ so that the new steady state equilibrium (without policy) has an interest rate of $2 \%$ per annum and average consumption of old people equals average consumption of young people in the economy. ${ }^{31}$

Table 8: Steady State Results with 3-Period Lived Households

\begin{tabular}{|c|c|c|c|c|c|c|c|c|c|}
\hline & $r_{p a}$ & $w$ & $Y$ & $H$ & $N$ & $\bar{m}$ & $\bar{s}$ & $E V^{s s}$ & $\%$ Ben. \\
\hline \hline Initial SS & $2 \%$ & 0.362 & 0.75 & 1.237 & 1.366 & $22 \%$ & $49.4 \%$ & & \\
\hline Ch. L. Ban & $1.99 \%$ & $0.22 \%$ & $-7.2 \%$ & $0.3 \%$ & $-7.3 \%$ & $0 \%$ & $50 \%$ & $-0.93 \%$ & $19.2 \%$ \\
\hline Free Educ. & $2.18 \%$ & $1.88 \%$ & $11.1 \%$ & $19.7 \%$ & $9.1 \%$ & $2 \%$ & $100 \%$ & $3.37 \%$ & $94.7 \%$ \\
\hline
\end{tabular}

${ }^{31}$ All previously calibrated parameters were re-calibrated, so that the new economy matches the same empirical targets as before. 
Comparing table 8 to table 3 we observe that the results of the extended model are almost identical to those obtained under the benchmark model, both qualitatively as well as quantitatively. School attendance and human capital accumulation is slightly lower in the no-policy steady state, since the substantial transfers to the elderly make it harder to spare the resources to sending children to school for the asset-poor (even if they have currently high labor productivity). Since the new post-policy steady states remain virtually the same under the extended model, now child labor bans have positive (but quantitatively small) effect on human capital accumulation. ${ }^{32}$

\section{Conclusions: Model Implications and Empir- ical Evidence}

We conclude by discussing how the results of our model compare with the historical record for the U.S. Our main model predictions are that child labor restrictions in the market sector are most strongly disliked by asset-rich capitalists and low-wage workers, and yield welfare gains only for high wage workers with little assets. Interpreting welfare gains and losses as support and opposition to such a policy reform, the predictions are very much in line with the historical evidence cited in section 2.2 above. Furthermore, our model predicts that education reforms are beneficial for a much larger fraction of the population, potentially explaining why in most states such reforms predated child labor restrictions. ${ }^{33}$ In addition, our results imply that, conditional on having implemented publicly provided education for everybody, neither a mandatory education law nor child labor restrictions are necessary to induce universal school attendance. Furthermore, the impact of introducing these additional laws on market child labor and schooling are small, consistent with the empirical findings for the 19th century U.S. of Moehling (1999) for child labor bans and Landes and Solmon (1972) for compulsory schooling. ${ }^{34}$

From our viewpoint, the most important normative predictions of our model with respect to the current discussion surrounding child labor in developing countries is that education reform is a much more effective way to curb child labor and to increase human capital accumulation and growth than preventing children from working in the market sector. The latter legal restriction (if not

\footnotetext{
${ }^{32}$ Also note that under free education some children still work in the formal sector, so that the additional introduction of a child labor ban has further (again quantitatively small) impacts on the time allocation of a child, in contrast to the benchmark model.

${ }^{33}$ In stating this we again acknowledge that without an explicit model of the political process no model-based statements about timing of policy changes can be made.

${ }^{34}$ The second half of the 19th century also appears to have been a period of constant wealth inequality, after a steep increase in the first half of the century. Our model predicts that, although child labor legislation, in particular an education reform has profound growth and welfare effects, its impact on wealth inequality is relatively minor, consistent with the historical record. But since many other economic factors affect wealth inequality and the empirical evidence for this time period is very sparse (see Williamson and Lindert (1980), p. 47 ), we do not want to emphasize this point too strongly.
} 
accompanied by free education provision for the poor), according to the predictions of our model, simply induces poor families to make their children work in low-return, informal activities, making them even poorer, without providing the necessary incentives to send their children to school. While these predictions of our model are in principle testable with a cross-developing-country data set that contains sufficient variation with respect to child labor laws and education policies, in practice almost all countries formally have child labor and compulsory education laws. Any empirical study therefore has to take the issue of enforcement of these laws very seriously. While we believe that such work is of high interest, its careful execution goes well beyond the scope of this paper and is therefore deferred to future research.

\section{References}

[1] Acemoglu, D. and J. Angrist (2000), "How Large Are The Social Returns to Education? Evidence from Compulsory Schooling Laws," 2000 NBER Macroannual, 9-59.

[2] Aiyagari, R. (1994), "Uninsured Idiosyncratic Risk and Aggregate Saving," Quarterly Journal of Economics, 109(3), 659-684.

[3] Baland, J. and J. Robinson (2000), "Is Child Labor Inefficient?," Journal of Political Economy, 108, 663-79.

[4] Basu, K. (1999), "Child Labor: Cause, Consequence, and Cure, with Remarks on International Labor Standards," Journal of Economic Literature, 37, 1083-1119.

[5] Basu, K. and P. Van (1998), "The Economics of Child Labor," American Economic Review, 88, 412-427.

[6] Becker, G. and R. Barro (1988), "A Reformulation of the Economic Theory of Fertility," Quarterly Journal of Economics, 103, 1-25.

[7] Ben-Porath, Y. (1967), "The Production of Human Capital and the Life Cycle of Earnings," Journal of Political Economy, 75, 352-365.

[8] Borjas, G. (1992), "Ethnic Capital and Intergenerational Mobility," Quarterly Journal of Economics, 107, 123-150.

[9] Carpena, L. and M. Santos (2000), "Economic Growth in Some Latin American and OECD Countries, 1960-1990," mimeo, University of Minnesota.

[10] Carter, S. and R. Sutch (1996), "Fixing the Facts: Editing of the 1880 U.S. Census of Occupations with Implications for Long-Term Labor Force Trends and the Sociology of Official Statistics," Historical Methods, 29, $5-24$. 
[11] Cunningham, H. (1996), "Combatting Child Labor: The British Experience," in Child Labor in Historical Perspective: Case Studies from Europe, Japan and Colombia, 41-55, UNICEF, New York.

[12] Dessy, S. (2000), "A Defense of Compulsory Measures Against Child Labor," Journal of Development Economics, 62, 261-75.

[13] Dessy, S. and J. Knowles (2001), "Why is Child Labor Illegal?" mimeo, University of Pennsylvania.

[14] Doepke, M. (2003), "Accounting for Fertility Decline During the Transition to Growth," mimeo, UCLA.

[15] Doepke, M. and F. Zilibotti (2003), "The Macroeconomics of Child Labor Regulation," mimeo, UCLA.

[16] Ensign, F. (1969), Compulsory School Attendance and Child Labor, Arno Press \& The New York Times, New York.

[17] Fernandez-Villaverde, J. (2001), "Was Malthus Right? Economic Growth and Population Dynamics," mimeo, University of Pennsylvania.

[18] Glomm, G. (1997), "Parental Choice and Human Capital Investment," Journal of Development Economics, 53, 99-114.

[19] Goldin, C. (1979), "Household and Market Production of Families in a Late Nineteenth Century American City," Explorations in Economic History, 16, 111-131.

[20] Grootaert, C. and R. Kanbur (1995), "Child Labour: An Economic Perspective," International Labour Review, 134, 187-203.

[21] Gupta, M. (2000), "Wage Determination of a Child Worker: A Theoretical Analysis," Review of Development Economics, 4, 219-28 .

[22] Hazan, M. and B. Berdugo (2002), "Child Labour, Fertility and Economic Growth," The Economic Journal, 112, 810-828.

[23] Hindman, H. (2002), Child Labor. An American History, M. E. Sharpe, New York.

[24] Jacoby, H. G. and E. Skoufias (1997), "Risk, Financial Markets, and Human Capital in a Developing Country," Review of Economic Studies, 64, 311-35.

[25] Krusell, P. and A. Smith (1998), "Income and Wealth Heterogeneity and the Macroeconomy," Journal of Political Economy, 106, 867-896.

[26] Landes, W. and L. Solmon (1972), "Compulsory Schooling Legislation: An Economic Analysis of Law and Social Change in the Nineteenth Century," Journal of Economic History, 32, 54-91. 
[27] Levison, D., K. S. Moe, and F. M. Knaul (2001), "Youth Education and Work in Mexico," World Development, 29, 167-88.

[28] Lucas, R. (1988), "On the Mechanics of Economic Development," Journal of Monetary Economics, 22, 3-42.

[29] Moehling, C. (1999), "State Child Labor Laws and the Decline of Child Labor," Explorations in Economic History, 36, 72-106.

[30] Nardinelli, C. (1990), Child Labor and the Industrial Revolution, Indiana University Press, Bloomington.

[31] Pallage, S. and C. Zimmermann (2000), "Buying Out Child Labor?" Center for Research on Economic Fluctuations and Employment, Working Paper No. 123.

[32] Psacharopoulos, G. (1997), "Child Labor versus Educational Attainment: Some Evidence from Latin America," Journal of Population Economics, $10,377-86$.

[33] Solon, G. (1992), "Intergenerational Income Mobility in the United States," American Economic Review, 82, 393-408.

[34] Trattner, W.I. (1970), The Crusade for the Children, Quadrangle Books, Chicago.

[35] U.S. Department of Commerce (undated) Historical Statistics of the U.S.

[36] U.S. Department of Education (1997), Digest of Educational Statistics, 1997, National Center for Educational Statistics, Washington, D.C.

[37] Williamson, J. G. and P. H. Lindert (1980), American Inequality: A Macroeconomic History, Academic Press, New York.

[38] Zimmerman, D. J. (1992), "Regression Toward Mediocrity in Economic Stature," American Economic Review, 82, 409-429. 